\section{REFERENCES}

1 Morice AH, and ERS Task Force committee members, The diagnosis and management of chronic cough. Eur Respir J 2004; 24: 481-492.

2 Palombini BC, Villanova CAC, Araujo E, et al. A pathologic triad in chronic cough: asthma, postnasal drip syndrome, and gastroesophageal reflux disease. Chest 1999; 116: 279-284.

3 Teramoto S, Matsuse T, Ouchi Y. Clinical significance of cough as a defence mechanism or a symptom in elderly patients with aspiration and diffuse aspiration bronchiolitis [letter]. Chest 1999; 115: 602-603.

4 Teramoto S, Yamamoto H, Yamaguchi Y, Ouchi Y, Matsuse T. A novel diagnostic test for the risk of aspiration pneumonia in the elderly. Chest 2004; 125: 801-802.

5 Teramoto S, Yamamoto H, Yamaguchi Y, Kawaguchi H, Ouchi Y. Nosocomial infections in adult intensive-care units. Lancet 2003; 362: 493.

6 Teramoto S, Kume H, Ouchi Y. Altered swallowing physiology and aspiration in COPD. Chest 2002; 122: 1104-1105.

7 Marumo K, Homma S, Fukuchi Y. Postgastrectomy aspiration pneumonia. Chest 1995; 107: 453-456.

8 Sekizawa K, Matsui T, Nakagawa T, Nakayama K, Sasaki H. ACE inhibitors and pneumonia. Lancet 1998; 352: 1069.

9 Teramoto S, Kume H, Fukuchi Y. Antihypertensive drugs in Japan. Lancet 2001; 357: 720-721.

10 Matsuse T, Oka T, Kida K, et al. Importance of diffuse aspiration bronchiolitis caused by chronic occult aspiration in the elderly. Chest 1996; 110: 1289-1293.

\section{From the author:}

Teramoto and colleagues have completely misunderstood the purpose of the ERS Task Force on diagnosis and management of chronic cough [1]. The document deals with patients who have had a cough for $>8$ weeks. It is not about patients who can't cough. To suggest in their opening paragraph that we neglect cough in the elderly is simply disingenuous. We deliberately separated chronic cough in children from that in adults since the aetiology is different. However, in adults the causes and treatment of chronic cough are not age related and the elderly were frequent attendees in the 13 studies quoted in table 1 which presents the accumulated experience of specialist cough clinics [1].

Decreased cough and aspiration are important clinical problems but they were not the subject of our discussions. Clearly neurological illness [2,3] and anatomical abnormality [4] can increase the likelihood of aspiration but this is neither age specific nor relevant to clinicians dealing with patients who present with isolated chronic cough.

Finally, an important function of documents such as the Task Force report is to provide a balanced overview of the literature. Teramoto and colleagues seem to have concentrated largely on their own work, which perhaps goes some way to explain the current debate.

\section{A.H. Morice}

Division of Academic Medicine, University of Hull, Castle Hill Hospital, Cottingham, UK.

\section{REFERENCES}

1 Morice $\mathrm{AH}$ and committee members. The diagnosis and management of chronic cough. Eur Respir J 2004; 24: 481-492.

2 Fontana GA, Pantaleo T, Lavorini F, Benvenuti F, Gangemi S. Defective motor control of coughing in Parkinson's disease. Am J Respir Crit Care Med 1998; 158: 458-464.

3 Dicpinigaitis PV, Grimm DR, Lesser M. Cough reflex sensitivity in subjects with cervical spinal cord injury. Am J Respir Crit Care Med 1999; 159: 1660-1662.

4 Fontana GA, Pantaleo T, Lavorini F, Mutolo D, Polli G, Pistolesi M. Coughing in laryngectomized patients. Am J Respir Crit Care Med 1999; 160: 1578-1584.

DOI: $10.1183 / 09031936.04 .00114704$

\title{
The hepatopulmonary syndrome: NO way out?
}

\section{To the Editors:}

The hepatopulmonary syndrome (HPS) is defined by the triad of chronic liver disease, abnormal pulmonary gas exchange (low arterial oxygen tension $\left(\mathrm{Pa}_{\mathrm{a}} \mathrm{O}_{2}\right)$ and transfer factor of the lung for carbon monoxide), and intrapulmonary vascular dilatation [1]. The recent editorial on HPS [2] suggests that "hunting endogenous vasodilators that reduce pulmonary vascular tone logically became a sound strategy for those whose quest was to unravel the missing 'molecular' link between the diseased liver and the affected lung". But, is this strategy actually so logical? The key feature of the intrapulmonary vascular dilatation in HPS is the intrapulmonary shunt shown physiologically by a low $\mathrm{Pa}_{\mathrm{a}} \mathrm{O}_{2}$ after $100 \%$ oxygen breathing, and anatomically by the passage of radiolabelled albumin macroaggregates $(20-60 \mu \mathrm{m}$ in diameter), or echobubbles, through the pulmonary capillary bed [3]. The striking feature pathologically is gross dilatation of capillaries in the alveolar septum, diameters of $100 \mu \mathrm{m}$, as compared with the normal $7-15 \mu \mathrm{m}$ being described [4]. Is it likely that endogenous vasodilators are responsible for "relaxing" alveolar capillaries to such an extent? Of course, endogenous vasodilators may play a part in "remodelling" these capillaries.

With regard to pulmonary gas exchange, two factors seem to operate in severe hepatopulmonary syndrome: 1) a 
hyperdynamic state with low pulmonary vascular resistance and rapid microvascular transit, and 2) vascular remodelling with dilatation of capillaries and a low transfer factor of the lung for carbon monoxide. After liver transplantation, arterial oxygen tension improves, but transfer factor of the lung for carbon monoxide often remains low [5], implying improvement in process 1 more than process 2 . Since pulmonary nitric oxide levels return to normal after orthotopic liver transplantation [6], nitric oxide is an unlikely cause of the pulmonary capillary dilatation. Figure 1 in the European Respiratory Journal editorial [2] focuses on pulmonary vascular smooth muscle, but it cannot be the only factor.

\section{J.M.B. Hughes}

National Heart and Lung Institute, Hammersmith Hospital Campus, Imperial College School of Medicine, London, UK.

\section{REFERENCES}

1 Lange PA, Stoller JR. The hepatopulmonary syndrome. Ann Intern Med 1995; 122: 521-529.

2 Dinh-Xuan AT, Naeije R. The hepatopulmonary syndrome: NO way out? Eur Respir J 2004; 23: 661-662.

3 Whyte MKB, Hughes JMB, Peters AM, Ussov W, Patel S, Burroughs AK. Analysis of intrapulmonary right to left shunt in the hepatopulmonary syndrome. J Hepatol 1998; 29: 85-93.

4 Davis HA, Schwartz DJ, Lefrak SS, Susman N, Schainker BA. Alveolar-capillary oxygen disequilibrium in hepatic cirrhosis. Chest 1978; 73: 507-511.

5 Ewert R, Mutze S, Schachschal G, Lochs H, Plauth M. High prevalence of pulmonary diffusion abnormalities without interstitial changes in long-term survivors of liver transplantation. Transpl Int 1999; 12: 222-228.

6 Rolla G, Brussino L, Coloagrande P, et al. Exhaled nitric oxide and impaired oxygenation in cirrhotic patients before and after liver transplantation. Ann Intern Med 1998; 129: 375-378.

DOI: 10.1183/09031936.04.00095604

\section{From the authors:}

Our recent editorial [1] argued that increased nitric oxide (NO) production is an important factor underlying the molecular mechanisms that cause pulmonary vascular dilatations in the hepatopulmonary syndrome (HPS). J.M.B. Hughes rightly points out that there is likely to be more to it than just the vasodilatory effects of $\mathrm{NO}$ to account for gross capillary dilatations typically found in the HPS. Indeed, there is little smooth muscle to relax in normal capillaries, and increased capillary diameters by a factor of 10 would be an unlikely consequence of vasorelaxation. We agree that other vasodilating mediators, such as carbon monoxide and the vasoactive intestinal peptide, along with an overexpression of the endothelin $B$ receptor [2, 3], are likely to be involved in a complex reversal of angiogenesis at the pulmonary arterioles and capillary network $[4,5]$. Capillaries and arterioles are not fixed structures, but are the net result of dynamic antagonistic processes of growth, repair, senescence and apoptosis. In HPS, this finely tuned balance would be disrupted in favour of dominant apoptosis and senescence, while pulmonary hypertension is the opposite situation of excessive uncontrolled angiogenesis. That the liver controls the constant remodelling of the pulmonary circulation is illustrated by the fact that pulmonary vascular dilatations occur when systemic veins are directly connected to the pulmonary circulation following surgical treatment of congenital heart defects [4-6]. These patients develop pulmonary vascular dilatations and pulmonary shunting, much like that observed in the HPS, and these abnormalities resolve after redirection of hepatic veins to the cavopulmonary connection [6].

J.M.B. Hughes also points out that after liver transplantation, pulmonary vascular resistance increases and arterial oxygen tension improves, but the carbon monoxide transfer factor remains low, suggesting a return to normal of arteriolar tone with restoration of pulmonary vasoreactivity to improve the matching of perfusion to ventilation, but persistently dilated pulmonary capillaries. Whether this is really the case remains uncertain. The carbon monoxide transfer factor cannot be anything but a very imperfect measure of pulmonary capillary calibre, and there are many causes of abnormally low carbon monoxide transfer factor in liver-transplanted patients. The pulmonary vascular dilatations after liver transplantation have been shown to reverse over time, although slowly and not always completely in the case of gross dilatations $[4,5,7]$. Here also, we agree with J.M.B. Hughes that a return to normal of endogenous nitric oxide production is unlikely to be the sole determinant of the reversal of pulmonary vascular structure and function to normal equilibrium state.

\section{R. Naeije* and A.T. Dinh-Xuan ${ }^{\#}$}

*Dept of Pathophysiology, Faculty of Medicine, Free University of Brussels, Brussels, Belgium. " Service de Physiologie-Explorations Fonctionnelles, Centre Hospitalier Universitaire Cochin, Université Paris V, Paris, France.

\section{REFERENCES}

1 Dinh-Xuan AT, Naeije R. The hepatopulmonary syndrome: NO way out? Eur Respir J 2004; 23: 661-662.

2 Imamura M, Luo B, Limbird JN, et al. Hypoxic pulmonary hypertension is prevented in rats with common bile duct ligation. J Appl Physiol 2004 (in press).

3 Chongsrisawat V, Ampai S, Chotivitayatarakorn $\mathrm{P}$, Sirisopikul T, Poovorawan Y. Relationship between vasoactive intestinal peptide and intrapulmonary vascular dilatation in children with various liver diseases. Acta Paediatr 2003; 92: 1411-1414.

4 Naeije R. Hepatopulmonary syndrome and portopulmonary hypertension. Swiss Med Wkly 2003; 133: 163-169.

5 Hervé P, Lebrec D, Brenot F, et al. Pulmonary vascular disorders in portal hypertension. Eur Respir J 1998; 11: 1153-1166.

6 Vettukantil JJ. Pathogenesis of pulmonary arteriovenous malformations: role of hepatopulmonary interactions. Heart 2002; 88: 561-563.

7 Rodriguez-Roisin R, Krowka MJ, Hervé P, Fallon MB. Pulmonary-hepatic vascular disorders. Eur Respir J 2004; 24: 861-880. 